\title{
CFD Analysis on Fluidized Bed Gasification of Rice Husk and Rice Straw
}

\author{
Singh Pushpendra, A. K. Srivastava* \\ Department of Mechanical Engineering, Shri Ramswaroop Memorial College of Engineering and Management, Lucknow, India \\ Email: sspushpendra44@gmail.com, *ak_srmcem@rediffmail.com
}

How to cite this paper: Pushpendra, S. and Srivastava, A.K. (2017) CFD Analysis on Fluidized Bed Gasification of Rice Husk and Rice Straw. Open Access Library Journal, 4: e3372.

https://doi.org/10.4236/oalib.1103372

Received: January 12, 2017

Accepted: February 24, 2017

Published: February 27, 2017

Copyright $\odot 2017$ by authors and Open Access Library Inc.

This work is licensed under the Creative Commons Attribution International License (CC BY 4.0).

http://creativecommons.org/licenses/by/4.0/

\begin{abstract}
In the work being presented, computational fluid dynamics (CFD) analysis on fluidized bed gasification of rice husk has been carried out. The multiphase Eulerian model was undertaken in the analysis. Due to the lack of computational space, two dimensional models of fluidized bed were created. The objective of the investigation was to study the effect of variation on velocity with varying particle sizes. The quality of synthesis gas was also taken into account. The inlet's superficial velocity was varied from $0.2 \mathrm{~m} / \mathrm{s}$ to $1.2 \mathrm{~m} / \mathrm{s}$ and diameter of rice husk varied from $0.0438 \mathrm{~mm}$ to $4.38 \mathrm{~mm}$. Based on obtained results, this may be concluded that minimum fluidization velocity decreases with increase in diameter of rice husk. The carbon conversion was found to be maximum for $0.7 \mathrm{~m} / \mathrm{s}$ velocity and carbon conversion increased for other velocities up to $96.9 \%$. The analysis was carried out using ANSYS FLUENT 14.0 non-commercial code.
\end{abstract}

\section{Subject Areas}

Mechanical Engineering

\section{Keywords}

Computational Fluid Dynamics, Fluidized Bed, Eulerian Model, Superficial Velocity, Carbon Conversion

\section{Introduction}

The study of gasification of materials using fluidized bed [1] gasifier has been a subject of interest among many researchers and scientists. This problem is very much important in replacing fossil fuels, particularly the fuels used in automobiles. The gasification in general is referred to a process which converts organic or fossil fuels based carbonaceous materials into $\mathrm{CO}, \mathrm{CO}_{2}$ and $\mathrm{H}$ by reacting material at high temperature $\left(>700^{\circ} \mathrm{C}\right)$, resulting into syngas which is itself a fuel. $\mathrm{Li}$ - 
teratures reveal that many researchers have performed the study on temperature, agglomeration and computational space, but insufficient progress has been reported on the effect of inlet superficial velocity and particle size of material. The key issue is to address the dependence of carbon conversion on the two aforementioned parameters. The previous studies by Ravi Inder Singh [2], 2010, developed the mathematical model for minimum fluidization velocity, causes of agglomeration and visualization of flow pattern; K G Mansaray et al. [3], 2000, developed the model that was based on material balance, energy balance, and chemical equilibrium relations. A CFD model for fluidized bed biomass gasifier is developed and the simulations are carried out to obtain the optimal condition for production of hydrogen rich gas (Zhou et al., [4], 2006). A non-premixed combustion model was used for biomass air-steam gasification in the gasifier. The simulation results were compared with the experimental data. The effects of the steam to biomass ratio $(\mathrm{S} / \mathrm{B})$, the equivalence ratio $(\mathrm{ER})$, and the size of the biomass particles on the hydrogen yield were studied. A 2-D Eulerian multi-fluid approach for gas-solid system in a CFB was carried out for simulation where Kinetic theory of granular flow (KTGF) had been used for describing the particle phase and $K$ - $\varepsilon$ based turbulent model had been used for gas phase (Yanping et al., [5], 2009). The model was used for the examination of the effects of the feeding configuration on the gas/solid two-phase flow, gas fluidization of solid particles (Toomey R. and Johnstone H. F., [6], 1952). The relaxation time of the bed was determined by the heat capacity of the fluidized solids and by the fraction of the heat released recycling to the bed as thermal feedback (Galgano et al., [7] and Boroduyla et al., [8]). Henceforth, in this work, the superficial velocity at inlet and the size of the particle are under consideration, which in turn affects the carbon conversion comprehensively. The simulations were run on the two-dimensional model using the Eulerian two phase models, solving the governing equations with the aid of ANSYS FLUENT CFD code (14.0). The obtained results can be served as a useful source material for future analytical and experimental investigations.

\section{Methods}

The entire work is focused upon the numerical simulation of two dimensional geometry of the fluidized bed gasifier. The process of analysis includes geometry modeling, discretization of computational domain, material selection, boundary conditions and then solver to run the calculations. The geometry modeling and discretization of computational domain was done on GAMBIT 2.2.30. Further simulation and post activities were run on non-commercial CFD code of FLUENT (ANSYS 14.0). The results fetched were then exported to plot the graphs and then compared to the previous works and the conclusions were drawn.

\section{Modeling}

The geometry size for the fluidized bed was taken from work of Ravi Inder Singh [2]. The vertical cross section of the bed was taken, the height of bed was $100 \mathrm{~cm}$ and the width was $28 \mathrm{~cm}$. The geometry was in two parts; one assumed having the 
rice husk/straw of height up to $40 \mathrm{~cm}$ and remaining having fluid (air).

The air at different velocity is assumed to be entering the gasifier from the bottom at the constant given value. The geometry can be seen in above Figure 1 .

\section{The governing equations:}

The Eulerian-Eulerian method is adopted for this study. The governing equations for the conservations of mass, momentum, energy and species transfer are given below [9]:

$$
\begin{gathered}
\frac{\partial \rho}{\partial t}+\nabla \cdot(\rho \vec{v})=0 \\
\frac{\partial}{\partial t}(\partial \vec{v})+\nabla \cdot(\rho \overrightarrow{v v})=-\nabla p+\nabla \cdot(\overline{\bar{\tau}})+\rho \vec{g}+\vec{F} \\
\frac{\partial}{\partial t}\left(\alpha_{q} \rho_{q} h_{q}\right)+\nabla \cdot\left(\alpha_{q} \rho_{q} \vec{u}_{q} h_{q}\right) \\
=\alpha_{q} \frac{\partial P_{q}}{\partial t}+\bar{\tau}: \nabla \vec{u}_{q}-\nabla \vec{q}_{q}+S_{q}+\sum_{p=1}^{n}\left(Q_{p q}+\dot{m}_{p q} h_{p q}-\dot{m}_{q p} h_{q p}\right) \\
\frac{\partial}{\partial t}\left(\rho Y_{i}\right)+\nabla \cdot\left(\rho \vec{v} Y_{i}\right)=-\nabla \cdot \vec{J}_{i}+R_{i}+S_{i} .
\end{gathered}
$$

Inter phase drag:

$$
C_{D}=\frac{D}{\frac{1}{2} \rho_{q}\left(v_{q}-v_{p}\right)^{2} A} .
$$

Lift force:

$$
F_{C}^{L}=r_{d} \rho_{c} C_{L}\left(v_{d}^{*}-v_{C}^{*}\right) \times\left(\omega_{c}^{*}+2 \Omega\right) .
$$

\section{Laminar finite rate model:}

The laminar finite-rate model computes the chemical source terms using Arrhenius expressions, and ignores the effects of turbulent fluctuations [10]. The net source of chemical species " $P$ " due to reaction is computed as the sum of the Arrhenius reaction sources over the $N_{R}$ reactions that the species participate in and is given as:

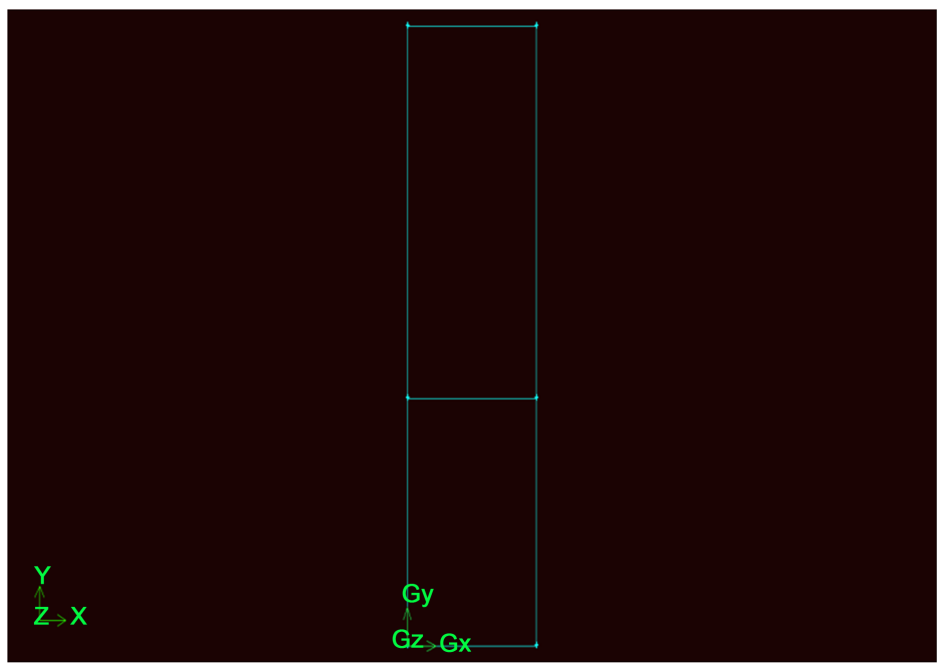

Figure 1. Geometry (as in GAMBIT). 


$$
R_{i}=M_{w, i} \sum_{r=1}^{N_{R}} \hat{R}_{i, r}
$$

The forward rate constant for the reaction $r, k_{f, r}$ is computed using Arrhenius expression:

$$
k_{f, r}=A_{r} T^{\beta r} e^{-E_{r} / R T} .
$$

\section{Analysis}

The Fluent 14.0 program was chosen for the numerical simulation. Prior to simulation in fluent the grid size was set for the computational domain. The two boundary continuums were set namely, bottom area and top area. The bottom area consists of rice husk/straw and the top area consists of air. Based on these, the grid sizes were set; the top area has fine mesh (as it has air in initial condition) as compared with the bottom area, which is having rice husk/straw. The uniformed quadrilateral cells were developed.

Total nodes $=281,281$.

Total quadrilateral cells $=280,000$.

For solving the equations, Phase Coupled method was used and first order upwind was implied for all the equations. Since the flow was multiphase, EulerianEulerian method was used where both gas and solid phases were treated as continua, inter-penetrating and interacting with each other everywhere in the computational domain. The single pressure field is assumed to be shared for all phases, in proportion to their volume fractions. The motion of each phase is governed by their mass and momentum conservation equations.

The following conditions were used (Table 1).

Biomass gasification is a multiphase problem between gases and rice husk particles. It is also a reactive flow that involves homogeneous reactions among gases and heterogeneous reactions between rice husk particles and gases. In this study, both gas phase (Phase 1) and rice husk phase (Phase 2) are solved by using Eulerian multiphase model. The gas phase is used for simulating both the steam inlet and the product gas outlet. This is achieved by including all the working species in one phase so that the mass and momentum equations are solved once per time

Table 1. Boundary conditions and other criteria.

\begin{tabular}{cc} 
Flow type & Laminar \\
\hline Granular viscosity model & Constant \\
Drag model & Syamlal-obrien \\
Frictional viscosity model & Schaeffer \\
Heat & Gunn \\
Number of iterations per time step & 80 \\
Convergence criterion & 0.0001 \\
Particle-particle restitution coefficient & 0.90 \\
Inlet velocities $[11]$ & $0.2,0.7,0.9,1.2(\mathrm{~m} / \mathrm{s})$ \\
Outlet condition & Atmospheric pressure
\end{tabular}


step. It consists of $\mathrm{O}_{2}, \mathrm{~N}_{2}, \mathrm{H}_{2} \mathrm{O}, \mathrm{H}_{2}, \mathrm{CO}, \mathrm{CO}_{2}$ and $\mathrm{CH}_{4}$. The properties of the species are taken from Ansys Fluent database. The gasifying agent is air considered at a constant velocity. Rice husk is considered as the feed material in this study. It is considered to be a granular phase. It consists of solid carbon $(C)$ representing char, $\mathrm{H}_{2} \mathrm{O}$ for the fuel's moisture and $\mathrm{CH}_{4}$ for the volatile matter (Table 2).

Eulerian multi-fluid model is adopted [12] [13] [14] where gas and solid phases are all treated as continua, interpenetrating and interacting with each other everywhere in the computational domain. The finite rate model is considered. Finite rate model is used to predict the reaction rate. The discretization scheme for momentum, energy and species all has been taken as first order upwind. For volume fraction of solid and gas phase Quick scheme is used.

\section{Results \& Discussions}

The simulation was run on Fluent to obtain the results. The graphs for velocity variation along the height of bed were plotted. Different diameters of rice husk for same velocity were simulated and also the variation in velocity was also observed keeping the diameter of rice husk same. The superficial velocities $0.2 \mathrm{~m} / \mathrm{s}, 0.7 \mathrm{~m} / \mathrm{s}$, $0.9 \mathrm{~m} / \mathrm{s}$ and $1.2 \mathrm{~m} / \mathrm{s}$ were run and diameters $0.0438 \mathrm{~mm}, 0.438 \mathrm{~mm}$ and $4.380 \mathrm{~mm}$ were tested.

Now as we go through the graphs, the point from where the curve starts to attain minimum fluctuation that is starts to be constant, the velocity of Phase 2 at that point is called minimum fluidization velocity.

In Figure 2, the superficial velocity or inlet velocity is equal to $0.2 \mathrm{~m} / \mathrm{s}$. It is evident from the curve that fluidization velocity of rice husk decreases with increase in the size of particle, the minimum fluidization velocity decrease from approx $2 \mathrm{~m} / \mathrm{s}$ to $1.5 \mathrm{~m} / \mathrm{s}$. Similarly, in Figure 3, the superficial velocity is $0.7 \mathrm{~m} / \mathrm{s}$ and it is evident that same trend of decrease in minimum fluidization velocity with increase in size of rice husk particle is found. It decreases from approx $2.75 \mathrm{~m} / \mathrm{s}$ to $1.25 \mathrm{~m} / \mathrm{s}$ for variation in particle diameter from $0.0438 \mathrm{~mm}$ to $4.38 \mathrm{~mm}$.

The similar trend of decreasing of minimum fluidization velocity with increase in diameter of rice husk particle is found as it is well depicted from plots. The superficial velocities in Figure 4 and Figure 5 are $0.9 \mathrm{~m} / \mathrm{s}$ and $1.2 \mathrm{~m} / \mathrm{s}$ respectively. However, if go across the variation in inlet superficial velocity and keeping the diameter of rice husk particle constant, it was the was no particular trend in

Table 2. Species mass fraction in rice husk and air.

\begin{tabular}{ccc}
\hline Species mass fraction & Rice husk & Air \\
\hline $\mathrm{H}_{2} \mathrm{O}$ & 0.0734 & \\
$\mathrm{C}(\mathrm{s})$ & 0.2046 & \\
$\mathrm{CH}_{4}$ & 0.5640 & \\
$\mathrm{~N}_{2}$ & & 0.23 \\
$\mathrm{O}_{2}$ & & 0.77 \\
\hline
\end{tabular}




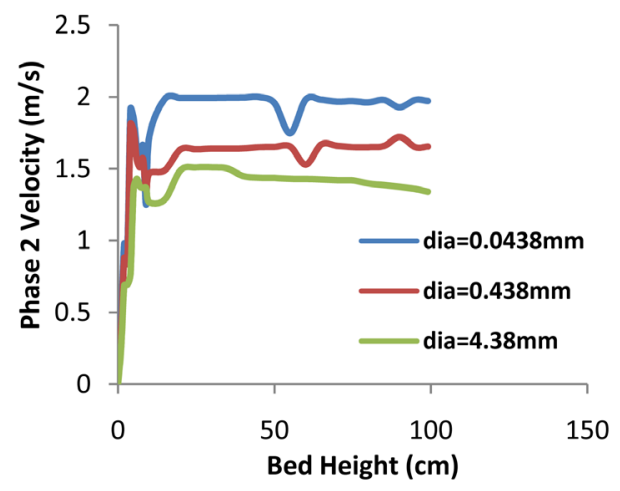

Figure 2. Inlet velocity $=0.2 \mathrm{~m} / \mathrm{s}$.

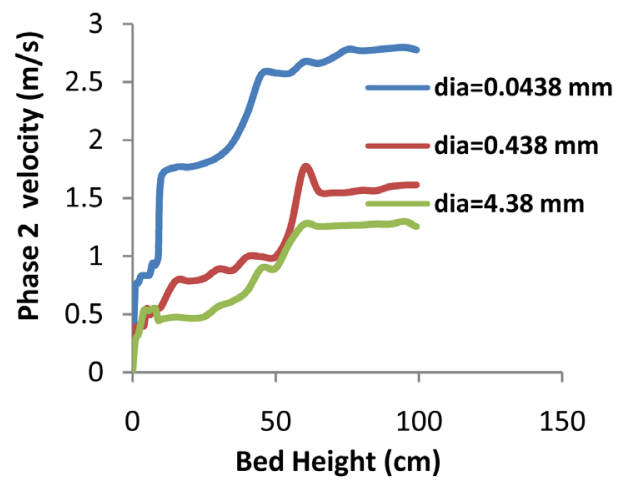

Figure 3. Inlet velocity $=0.7 \mathrm{~m} / \mathrm{s}$.

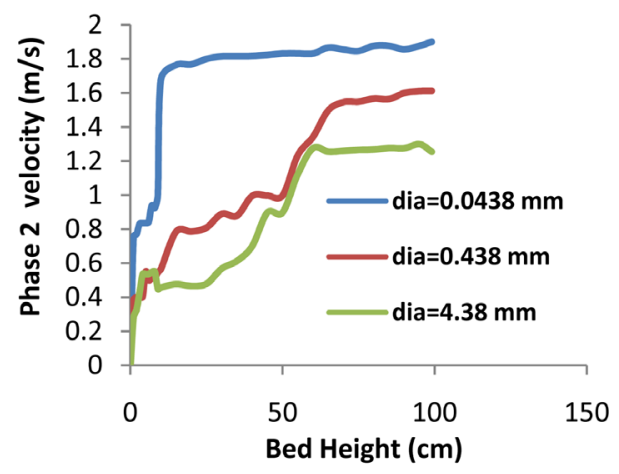

Figure 4. Inlet velocity $=0.9 \mathrm{~m} / \mathrm{s}$.

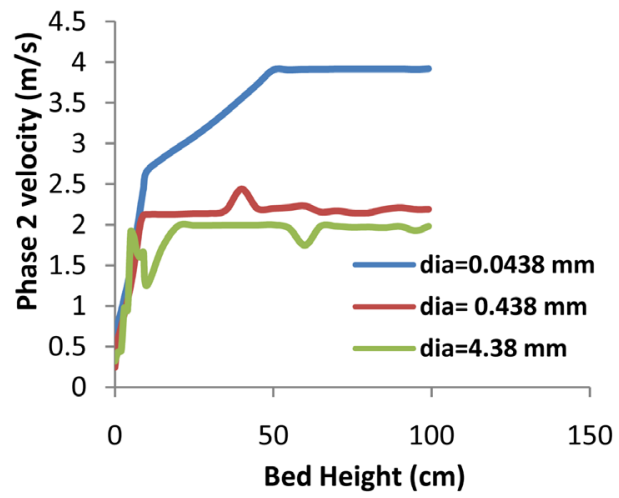

Figure 5. Inlet velocity $=1.2 \mathrm{~m} / \mathrm{s}$. 
the minimum fluidization velocity as it firstly increase then decreases and then again increases. This is well evident from curves obtained as shown in Figures $2-4$.

Also the velocity of phase 2 particles is also found to be zero at the wall of the gasifier and is maximum at the center line along which the graphs have been plotted.

The region near the fuel inlet shows a particularly concentrated region for the gaseous species of $\mathrm{CO}, \mathrm{H}_{2}$ and $\mathrm{CH}_{4}$. This region signifies the accumulation of devolatilisation products as the fuel is introduced to the bed at this point. The products then mix through the bed along with the products of heterogeneous reactions from the lower bed region to continually trigger further reactions.

The simulation results are compared to the actual experimental data. It is noticeable that $\mathrm{N}_{2}$ and $\mathrm{CO}_{2}$ are overestimated, while $\mathrm{H}_{2}$ is underestimated as shown in Figure 6. The $\mathrm{CO}$ and $\mathrm{CH}_{4}$ mass fractions show acceptable agreement with the experimental data taken from [2] and [15] i.e., study by Ravi Inder Singh, 2010, where the mathematical model for minimum fluidization velocity, causes of agglomeration and visualization of flow pattern was being done and by Ramirez, 2007, where gasification was done on pilot scale.

\section{Conclusions}

Based on the results obtained from simulation, following conclusions were drawn:

1) Increasing the inlet superficial velocity makes the flow development faster and has a strong influence on the velocity of rice husk.

2) The velocities of the smaller particles are larger than those of the bigger particles in the lower zone due to the attainment of high slip on the bottom side.

3) The minimum fluidization velocity increases with decrease in the diameter size of rice husk particle and vice-versa.

4) There is no specific trend followed when superficial velocity is varied and diameter of rice husk particle is kept same; it may increase or decrease as observed.

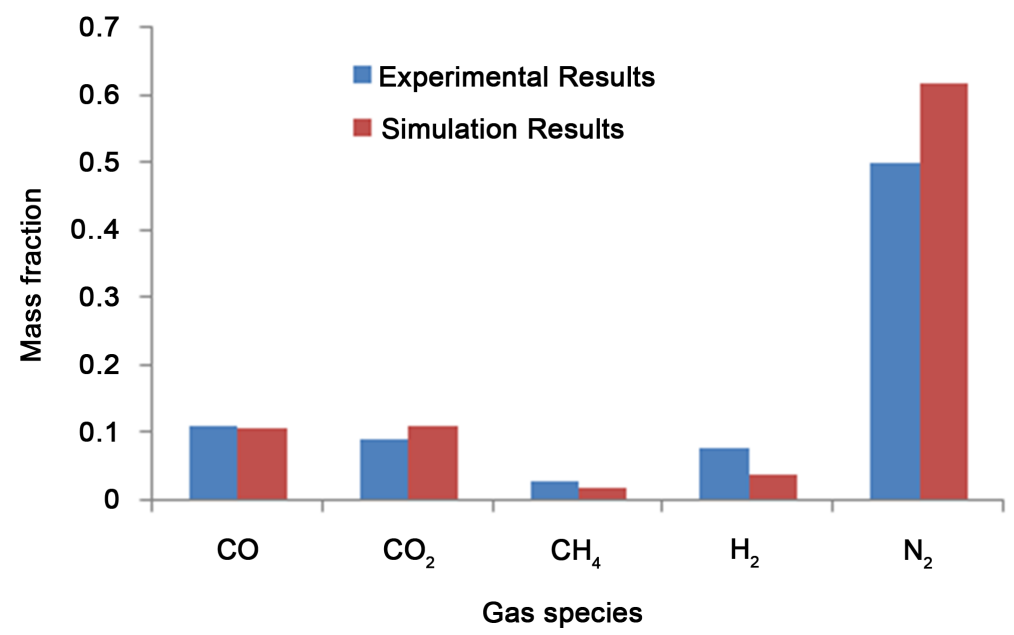

Figure 6. Experimental and simulation results. 
5) The reactions in the instantaneous gasification model occur very fast and finish very quickly with an indicating $100 \%$ carbon conversion for superficial velocity $0.7 \mathrm{~m} / \mathrm{s}$ and can be increased up to $96.9 \%$ for other considered superficial velocities.

\section{Acknowledgements}

This research was supported by Department of Mechanical Engineering, ShriRamswaroop Memorial College of Engineering and Management, Lucknow, India. We are also grateful to Dr. Pandba Patro, for his insight in the field of Computational Fluid Dynamics, which has made significant contribution to this effort.

\section{References}

[1] Kunii, D. and Levenspiel, O. (1968) Bubbling Bed Model for Kinetic Processes in Fluidized Beds. Industrial \& Engineering Chemistry Process Design and Development, 7, 481-492. https://doi.org/10.1021/i260028a001

[2] Singh, R.I. (2010) Study of Performance of an Atmospheric Bubbling Fluidized Bed Combustor Using Rice Waste. Thapar University, Patiala.

[3] Mansaray, K.G., Al-Taweel, A.M., Ghaly, A.E., Hamdullahpur, F. and Ugursal, V.I. (2000) Mathematical Modeling of a Fluidized Bed Rice Husk Gasifier: Part I-Model Development. Energy Sources, 22, 83-98. https://doi.org/10.1080/00908310050014243

[4] Rui, X., Zhang, M., Jin, B., Huang, Y. and Zhou, H. (2006) High-Temperature Air/Steam-Blown Gasification of Coal in a Pressurized Spout-Fluid Bed. Energy \& Fuels, 20, 715-720. https://doi.org/10.1021/ef050233h

[5] Li, Y., Ma, B., Hu, J. and Zhao, K. (2009) Numerical Simulation of the Hydrodynamics of Gas/Solid Two-Phase Flow in a Circulating Fluidized Bed with Different Inlet Configurations. Chemical Engineering \& Technology, 32, 964-970. https://doi.org/10.1002/ceat.200800455

[6] Toomey, R. and Johnstone, H.F. (1952) Gas Fluidization of Solid Particles. Chemical Engineering Progress, 48, 220-226.

[7] Galgano, A., Salatino, P., Crescitelli, S., Scala, F. and Maffettone, P. (2005) A Model of the Dynamics of a Fluidized Bed Combustor Burning Biomass. Combustion and Flame, 140, 371-384. https://doi.org/10.1016/j.combustflame.2004.12.006

[8] Borodulya, V.A., Didalenko, V.I., Palchonok, G.I. and Stanchitis, L.K. (1995) Fluidized Bed Combustion of Solid Organic Wastes and Low-Grade Coals: Research and Modeling. Proceedings of the 13th International Conference of Fluidized Bed Combustion, Orlando, 7-10 May 1995, 935-942.

[9] Patankar, S.V. (1980) Numerical Heat Transfer and Fluid Flow. Taylor \& Francis Publishers, New York.

[10] Yu, L., Lu, J., Zhang, X. and Zhang, S. (2007) Numerical Simulation of the Bubbling Fluidized Bed Coal Gasification by the Kinetic Theory of Granular Flow (KTGF). Fuel, 86, 722-734. https://doi.org/10.1016/j.fuel.2006.09.008

[11] Peng, B., Zhu, J. and Zhang, C. (2011) A New Approach to Specify the Inlet Boundary Conditions for Computational Fluid Dynamics (CFD) Modeling of Hydrodynamic Behavior of a Circulating Fluidized Bed (CFB) Riser. Industrial \& Engineering Chemistry Research, 51, 2152-2165. https://doi.org/10.1021/ie200916c

[12] Gerber, S., Behrendt, F. and Oevermann, M. (2010) An Eulerian Modeling Ap- 
proach of Wood Gasification in a Bubbling Fluidized Bed Reactor Using Char as Bed Material. Fuel, 89, 2903-2917. https://doi.org/10.1016/j.fuel.2010.03.034

[13] Zhou, M., Yan, L., Guo, Q. and Zhu, Q. (2006) Non-Premixed Combustion Model of Fluidized Bed Biomass Gasifier for Hydrogen-Rich Gas. Chinese Journal of Chemical Physics, 1, 131-136. https://doi.org/10.1360/cjcp2006.19(2).131.6

[14] Gidaspow, D. (1994) Multiphase Flow and Fluidization: Continuum and Kinetic Theory Descriptions. Academic Press, New York.

[15] Ramirez, J.J., Martinez, J.D. and Petro, S.L. (2007) Basic Design of a Fluidized Bed Gasifier for Rice Husk on a Pilot Scale. Latin American Applied Research, 37, 299306. 


\section{Nomenclature}

\begin{tabular}{|c|c|}
\hline$\alpha$ & Volume Fraction \\
\hline$\rho$ & Density of Fluid $\left(\mathrm{kg} / \mathrm{m}^{3}\right)$ \\
\hline v & Velocity $(\mathrm{m} / \mathrm{s})$ \\
\hline$p$ & Pressure $(\mathrm{Pa})$ \\
\hline$\overline{\bar{\tau}}$ & Stress-strain Tensor $(\mathrm{Pa})$ \\
\hline$\vec{g}$ & Acceleration due to Gravity $\left(\mathrm{m} / \mathrm{s}^{2}\right)$ \\
\hline$\mu$ & Viscosity $(\mathrm{kg} / \mathrm{m} \cdot \mathrm{s})$ \\
\hline$h$ & Specific Enthalpy (J/kg) \\
\hline$q$ & Heat Flux $(J)$ \\
\hline$\nabla$ & Gradient \\
\hline$\beta$ & Coefficient of Thermal Expansion \\
\hline$Y_{i}$ & Mass Fraction of Species \\
\hline$N$ & Total Number of Phases \\
\hline$R$ & Rate of Reaction \\
\hline$T$ & Temperature (K) \\
\hline$K$ & Rate Constant \\
\hline$j$ & Species \\
\hline$t$ & Turbulent \\
\hline$r$ & Reaction \\
\hline$p$ & Phase \\
\hline$s$ & Solids \\
\hline$q$ & Phase \\
\hline
\end{tabular}

Submit or recommend next manuscript to OALib Journal and we will provide best service for you:

- Publication frequency: Monthly

- 9 subject areas of science, technology and medicine

- Fair and rigorous peer-review system

- Fast publication process

- Article promotion in various social networking sites (LinkedIn, Facebook, Twitter, etc.)

- Maximum dissemination of your research work

Submit Your Paper Online: Click Here to Submit

Or Contact service@oalib.com 